\title{
Research
}

\section{The Evolution of the Maine Lobster V-Notch Practice: Cooperation in a Prisoner's Dilemma Game}

\author{
James Acheson $^{1}$ and $\underline{\text { Roy Gardner }}^{2}$
}

\begin{abstract}
The Maine lobster industry is experiencing record high catches because, in all probability, of an effective management program. One of the most important conservation measures is the V-notch program that allows fishermen to conserve proven breeding females by notching the tails of egg-bearing lobsters. Such marked lobsters may never be taken. Although thousands of lobster fishermen participate, it is a voluntary practice. The genesis of this practice is not easily explained, because V-notching poses a prisoner's dilemma problem that gives fishermen an incentive to avoid the practice. The most common explanations for ways to overcome prisoner's dilemma problems will not work in the case of the V-notch. An unusual combination of factors explains the V-notch program: (1) a strong belief among those in the industry that the V-notch is effective in conserving the lobster stock; (2) a low discount rate because the long-term gains from V-notching are higher than the one-time gain from defection; (3) a gain in reputation for those who V-notch. At the start of the 20th century, fishermen did not V-notch; by the end of the century, $\mathrm{V}$-notching was common. We explain the change in strategies using a three-parameter evolutionary model that emphasizes the importance of culture change.
\end{abstract}

Key Words: collective action; evolutionary game theory; lobster; Maine; prisoner's dilemma; V-notch program

\section{INTRODUCTION}

Catches of American lobster (Homarus americanus) in Maine are at record high levels. Although the reason for these high catch levels is not known for certain, there is growing consensus that they are due to a long history of highly effective regulations that the industry has helped develop. Most of these regulations are formal laws passed by the state legislature and the federal government. One of the most effective conservation measures, however, is the $\mathrm{V}$-notch practice, a voluntary program in which thousands of Maine fishermen participate. Vnotching lets fishermen take advantage of a program in which the state buys back from lobster pounds any lobsters that have extruded eggs while in captivity. Wardens mark these lobsters by notching a V in their tail. Such V-notched lobsters may not be harvested as long as the V-notch shows. To augment the size of the breeding stock, many fishermen also cut notches in the tails of egged lobsters before returning them to the ocean. There are now hundreds of thousands of V-notched lobsters in Maine waters.

We discuss the genesis of Maine's lobster V-notch practice, which leads us into the middle of one of the most important sets of questions facing social scientists: namely, how do people solve the problem of cooperation? Explaining the V-notch is difficult and necessitates an unusual explanation.

Among rational choice theorists, there is consensus that rules to constrain individuals will improve outcomes in collective action dilemmas. There is no consensus about the conditions under which such rules will be developed. There is general agreement that it is easier to develop rules if the group is small, if people know a good deal about each other's histories, if the game is played repeatedly, and if it is possible to enforce the rules (Taylor 1982, Elster 1989, Coleman 1990, North 1990, Ostrom 1990, Knight 1992, Wade 1994). Under these circumstances, people know who is likely to 
cooperate and can monitor and identify shirkers. Another factor affecting the willingness to cooperate is the ability to curb free riders, because people will not invest in public goods or rules if most of the benefits go to those who did not sacrifice to produce them. A large number of factors have been mentioned by various theorists as affecting cooperation, including homogeneity, discount rate, political entrepreneurship, trust, community, and ability to change the rules (Ostrom 1990, 2000a, 2000b, Agrawal 2002).

In addition, several theories have been developed about the mechanisms by which rules are produced, including those of Lewis (1969), Sugden (1986), North (1990), and Knight (1992), as well as work by those concerned with adaptation and evolution (Axelrod 1984, Fehr and Gächter 2000, Nowak and Sigmund 2005, Henrich and Henrich 2007). Some of these factors play a role in the V-notch.

Common-pool resources, including marine fisheries, present a classic collective action dilemma. In such situations there is a divergence between what is in the interest of individuals and what is optimal for society (Elster 1989, Taylor 1990). In the case of fisheries, it is in the self-interest of individual skippers to get as many fish as possible even though a rule constraining exploitive effort would result in a sustainable fishery and larger catches. In most fisheries, the conditions necessary for rules to constrain fishing effort have been largely absent, with the result that many fish stocks are dangerously overexploited (Hardin 1968, Acheson 1989, McGoodwin 1990, Wade 1994, Thompson 2000). The lobster fishery is different in that it has repeatedly solved its collective action dilemmas (Acheson 2003).

\section{THE MAINE LOBSTER INDUSTRY}

The American lobster is found in the inshore waters off the Atlantic coast of North America from Newfoundland to Virginia. Lobster biologists and fishermen measure lobsters on the carapace, i.e., from the eye socket to the back of the body shell. Scientists record measurements in millimeters. The law is stated in inches. In this article, when we are speaking of legal measures, inches will be used. When lobsters extrude eggs, they remain attached to their bodies for a period of months. They are Vnotched during this period when eggs are visible.
The lobster fishery is an inshore trap fishery. Most lobster boats are between 10.6 and $12 \mathrm{~m}$ long and are operated by one- or two-person crews who fish an average of 575 wire traps. Currently there are about 6000 lobster boats in Maine (Acheson 2003). The industry is highly territorial. To catch lobster, a person must gain acceptance by a group of people fishing from one harbor, called a "harbor gang" (Acheson 1988). Once admission is gained, the fisherman can fish only in this group's territory; territories average about $200 \mathrm{~km}^{2}$. They are defended in some cases by the surreptitious destruction of lobster gear (Acheson 1988, 2003).

The people who fish from the same harbor are some of the most important people in a fisherman's life. Most live in the same town as the harbor. Many are members of long-established families, which have commonly intermarried (Acheson 1988). Harbor gangs are also reference groups. They are the yardstick by which one measures one's standing and level of success. There is great competition to be a good fisherman; such "highliners" are held in high esteem and emulated by others.

\section{Maine lobster laws}

Over the course of the past 120 years, the Maine legislature has passed five important laws to manage the fishery: (1) egg-bearing females may not be taken; (2) the double-gauge law, which makes it illegal to take lobsters less than 3.25 inches on the carapace, thereby protecting the juveniles; it is also illegal to take lobsters more than 5 inches on the carapace, which protects the large reproductivesized lobsters that extrude far more eggs in proportion to weight than smaller lobsters; (3) lobsters can only be caught in traps, and traps must be equipped with escape vents, which allow juvenile lobsters to escape; (4) V-notched lobsters must not be taken; and (5) in 1995, the Zone Management Law, which changed many aspects of lobstering. The Zone Management Law divides the coast into seven zones run by zone councils elected by lobster license holders. This law established an apprenticeship program for the state. The zones have different trap limits and limited-entry rules.

Although the majority of fishermen today support the conservation laws, they came about in the course of drawn-out, acrimonious disputes between industry factions that had different interests to 
pursue. The advent of these laws has been covered in other publications (Acheson and Knight 2000, Acheson 2003).

\section{Catches}

The fortunes of the lobster industry have varied considerably over the past 120 years. In the 1920 s and 1930s, the period of the lobster bust, economic conditions in the industry were terrible. Catches were low, and prices in the Depression were also low (Acheson and Steneck 1997). Forty percent of lobster fishermen went out of business between 1928 and 1930, and many of those remaining could barely earn a living in the fishery (Correspondence of the Commissioner 1933). The low stock sizes were produced, in some part, by the widespread violation of the conservation laws. In the early decades of the 20th century, eggs were scrubbed off female lobsters so the lobsters could be sold, and there was a large-scale trade in short lobsters. Millions of kilograms of undersized lobsters were shipped to Massachusetts by boat, train, and truck (Acheson 2003).

From World War II to 1989, catches hovered around 7.5 million kg per year (Acheson 2003). From 1989 to the present, catches have been at record-high levels despite decades of intense exploitation. In every year after 2000 , catches have exceeded 22.7 million $\mathrm{kg}$. This boom is due to environmental factors, e.g., favorable water temperature and low predation by large finfish, working in tandem with conservation laws (see Acheson and Steneck 1997).

\section{DATA AND METHODS}

The data on which this article is based were collected using different techniques: (1) use of historical and archival records, especially the Correspondence of the Commissioner in the Maine State Archives; (2) a questionnaire sent to a random sample of 3000 lobster license holders in the spring of 2009; (3) personal interviews in the summer of 2009 with 22 men who were between 85 and 98 years old. Of the 3000 mailed surveys, 701 , or $23 \%$, were returned, and the results were analyzed using SPSS. The personal interviews focused on conditions in the lobster industry in the 1920s, 1930s, and 1940s. A number of topics were discussed in these interviews, including the V-notch. In our interview concerning the V-notch, we focused on five questions: When did you start V-notching? Why did you begin to Vnotch? How many others in your harbor were $\mathrm{V}$ notching when you began? When did most of the fishermen in your harbor begin to V-notch? When you started to fish for lobster, were most people convinced the practice helped to conserve the stock?

\section{THE V-NOTCH PRACTICE}

For most of the 20th century, the practice of $\mathrm{V}$ notching was voluntary. The law prohibited fishermen from taking egg-bearing females, but there was no law making it mandatory for a notch to be cut in the tail. However, many fishermen did so voluntarily even though it is impossible to be certain who was $\mathrm{V}$-notching because what happens on a boat cannot be monitored by anyone who is not on the boat.

The V-notch program began in 1917 when the Maine legislature passed a law allowing the wardens to purchase lobsters that had extruded eggs in pounds to stop the pound owners from scrubbing the eggs off and selling them. Lobster pounds are enclosed areas in the ocean where lobsters are stored for a period of months prior to sale. The wardens released them after they were marked with a hole punched in their tail (Legislative Record 1917, Maine Commission of Sea and Shore Fisheries 1926). Fishermen were forbidden to take lobsters with punched tails (Kelly 1990). By the mid-1930s, however, the seeder program had expanded to where the state of Maine was purchasing " 60,000 pounds of seed lobster, from the fishermen through dealers, at market prices" (Maine Department of Sea and Shore Fisheries 1936:11). In 1948, the law was changed so that lobsters were marked by a V-shaped notch in the tail rather than a round hole (Laws of Maine 1947). From that time on, the program became known as the V-notch program.

The V-notch program is built on the idea that conserving females will result in increased recruitment and catches. Putting a notch in the tail ensures the lobster will not be taken when the eggs have dropped off. Even before 1900, lobster biologists were convinced of the value of conserving large females, especially egged females (Martin and Lipfert 1985). Fishermen were not. In legislative hearings in the early decades of the 20th century, fishermen repeatedly opposed bills to conserve large lobsters. When the law passed in 1933 prohibiting harvesting of big lobsters, a large 
group of fishermen from eastern Maine tried to have it overturned by referendum (Acheson 2003).

A change in lobster fishermen's attitudes was detectable in the 1930s. Many became convinced that illegal activity was the cause of the low catches they were experiencing. They began to report violations to the commissioner and warden force. They also began to support conservation laws, including the oversize measure (Acheson and Gardner 2010). A few people, according to key informants, began to $\mathrm{V}$-notch lobsters at this time.

By the mid-1940s, a decided change in the culture of the lobster fishery had taken place. More lobster fishermen were interested in conservation and increasing numbers of them were convinced that conserving big lobsters was good (Acheson and Gardner 2010). Key-informant interviews indicate that $\mathrm{V}$-notching got a big boost when men returning from military service in World War II took up the practice in increased numbers. Eddie Blackmore, past president of the Maine Lobstermen's Association, said,

We decided that if we were going to keep it [the fishery] going, we needed to do something to replenish the supply. We knew that $V$-notched lobsters were protected and we decided to put more lobsters in that category. When I had an especially good day, I would notch one or two big egged females as a way of investing in the future of the industry. We didn't have to do it, but the idea caught on and a lot of people began to preserve the proven eggers in this way.

The continued improvement in catch levels from the mid-1930s also helped to motivate people to $\mathrm{V}$ notch. Fishermen had evidence that something was helping the fishery and they gave the V-notch a major amount of the credit.

By the 1980s, the V-notch had achieved sacrosanct status. In the view of many fishermen, the V-notch practice is one of the primary reasons for the current large stock of lobsters (Acheson 2003). A fisherman said, "If you do away with that law [the V-notch], you do away with the industry. It is that important."

Support for the V-notch has grown over the decades among fishermen. By the 1990s, thousands of fishermen voluntarily cut notches in the tails of the egged females they caught. A 1995 study by Robert
Bayer and students found that more than $60 \%$ of egg-bearing females had a V-notch (Lobster Institute 1995). A study completed by the Maine Department of Marine Resources in 2000 showed that the proportion of egged lobsters with a V-notch had grown to $80 \%$ (Carl Wilson, DMR, personal communication). Since 2000 , the rate has stayed about $80 \%$. In 2003, the legislature passed a law making it mandatory for fishermen to $\mathrm{V}$-notch all egged females. There is, however, no way to enforce this law. One can only monitor whether a person is $\mathrm{V}$-notching the gravid female lobsters by placing an enforcement officer on every boat. V-notching is still de facto voluntary.

In the latter part of the 20th century, state and federal biologists argued that both the $\mathrm{V}$-notch practice and the oversize law should be abolished. They considered the $\mathrm{V}$-notch a source of infection and the oversize law as doing little good because so few lobsters reached sanctuary size. They wanted the minimum size increased to 3.5 inches. In 1971, all of these proposals became part of the state-federal plan, which would have established uniform laws throughout New England. The Maine lobster industry was violently opposed to this plan. Fishermen believed the V-notch and the oversize law were effective and an increase in the minimum size would produce larger and less marketable lobsters (Acheson 2003).

After months of nasty confrontations, a compromise bill was passed retaining the $\mathrm{V}$-notch and the oversize law. The biologists continued to insist that the V-notch should be abolished, until 2000 when new scientific studies convinced them that it was an effective management tool to help conserve reproductive-sized lobsters and increase recruitment (Lobster Technical Committee 2000, Gibson and Angell 2006, DeAngelis et al. 2010).

V-notch protection was extended only to lobsters landed in Maine. That changed after 1995 when the Atlantic States Marine Fisheries Commission (ASFMC), which had taken over lobster management in federal waters between 3 and 200 miles, passed Amendment 3 to the lobster plan, stipulating that V-notched lobsters would be protected from Maine to Cape Cod, Massachusetts. The Maine delegation worked hard for this rule to stop fishermen from New Hampshire and Massachusetts from taking lobsters that were Vnotched in Maine. 


\section{THE CULTURE OF THE LOBSTER INDUSTRY AND THE V-NOTCH}

Currently, the Maine lobster industry has a widespread conservation ethic. Groups of fishermen have lobbied for management laws; they believe the large stock of lobsters and record high catches are because of those laws (see Acheson and Knight 2000, Acheson 2003).

Belief in the effectiveness of current lobster management laws is strongly demonstrated in the results of our 2009 mail survey of lobster fishermen. One of our questions was "How effective are each of the following laws in conserving the lobster stock?" The data in Table 1 show that at least $75 \%$ of respondents rated all of these laws very effective. Ninety percent or more rated the V-notch and the prohibition on taking egged lobsters to be very effective.

In the culture of lobster fishing, the V-notch is especially valuable because fishermen are convinced the secret of management is to conserve juveniles and large reproductive-sized lobsters. The juveniles are conserved by the minimum size law and the large reproductive-sized lobsters by the Vnotch and the oversize law (Acheson and Steneck 1997). One of the tenets of lobster fishing is that the industry as a whole and every individual in it gains a good deal from V-notching through increases in future catches. Fishermen are willing to sacrifice time to this end. Some phrase their support in terms of personal gain. One said, "It is just helping yourself in the long run." Far more see V-notching as supporting a joint effort. "We have to maintain the stock of lobsters we all depend on," said one. Others see it as an investment for future generations. They also hope their children will be able to earn their living in the industry. The V-notch is a means to that end. This conclusion is supported by interviews with key informants and the results of our large-scale mail survey in 2009. Analysis of information given by 695 fishermen revealed they had been in the fishery for an average of 27.7 years. Of the 695 fishermen who gave information on plans for the future, $91.9 \%$ said they would remain in the lobster industry although $50.1 \%$ said it would be difficult do so. Another question asked whether they agreed or disagreed with the statement, "I would like my children to enter the lobster industry." Of the 671 who responded, only $10.9 \%$ said they strongly disagreed.
Fishermen take some pride in helping to maintain the lobster stocks. Carl Wilson (personal communication), Maine's lobster biologist, points out that fishermen who V-notch talk about it. "They want others to know what they are doing. Those who do not V-notch say nothing." Conversely, there is a general feeling that those who do not V-notch are not contributing to a common good. One fisherman said of a non-V-notcher, "He is just a freeloader. He is living off us."

In the mid-1980s when federal scientists were attempting to abolish the practice of $\mathrm{V}$-notching, a number of well-regarded fishermen strongly defended this practice (Plante 1986, Acheson 2003). Their successful defense of the V-notch unquestionably elevated them in the eyes of their fellow fishermen. It may also have persuaded others to take up the practice.

\section{V-NOTCH: A PRISONER'S DILEMMA}

Understanding the genesis of the V-notch is particularly difficult because it can best be considered a prisoner's dilemma game, a type of non-zero-sum game with a payoff structure that makes cooperation difficult. In a prisoner's dilemma, all players have a dominant strategy to defect, even though the equilibrium outcome is worse than if they had played their dominated strategy. That is, if both players cooperate in Vnotching, both get good rewards. If both defect, the result is low payoffs for both. Unfortunately, if one defects and the other does not, the defector gets a large reward and the other gets a low payoff. The high reward for defection motivates both players to defect, with the result that they get the worst of all possible payoffs. Defection dominates cooperation even though cooperation by both would bring higher payoffs, and a more efficient Nash equilibrium (Gardner 2003). This is the problem inherent in all collective action dilemmas (Elster 1989, Taylor 1990).

In the case of the V-notch, individuals incur a cost in terms of the time it takes to cut the notch and put the lobster back in the water. However, they can be certain of no personal payoff. Under these circumstances, it is only rational to refuse to Vnotch. Fortunately, however, many fishermen Vnotch lobsters despite the logic of the prisoner's dilemma. Why they engage in this cooperative 
Table 1. Fishermen's responses to the question 'How effective are each of the following laws in conserving the lobster stock?'

\begin{tabular}{lcccc}
\hline \hline Law & Very Effective (\%) & $\begin{array}{c}\text { Somewhat Effective } \\
(\%)\end{array}$ & Not Effective (\%) & Number Answering \\
\hline Minimum size measure & 90.4 & 8.7 & .9 & 686 \\
Maximum size measure & 61.9 & 27.5 & 10.6 & 679 \\
V-notch & 90.9 & 7.6 & 1.5 & 685 \\
Traps only & 76.6 & 16.9 & 6.4 & 668 \\
Escape vent & 77.7 & 18.7 & 3.6 & 691 \\
Prohibition on taking & 95.5 & 3.6 & .9 & 689 \\
eggers & & & & \\
\hline
\end{tabular}

behavior can only be understood by considering the costs and benefits involved.

\section{MODELING THE V-NOTCH}

What factors have allowed the lobster industry to overcome the dilemma it faces? To answer this question, we have developed a simple evolutionary model that permits analysis of the changes in the industry (see Appendix 1 for an abbreviated version of this model).

There are two aspects to V-notching which are highlighted by this model. First, this is a tipping point model that has been used to predict the levels of cooperative behavior. If a high percentage of a population cooperates, others will follow; if only a few cooperate, then smaller and smaller numbers will cooperate to avoid being a "sucker" (Poteete et al. 2010). If this applies to the V-notch, it means that the payoffs to fishermen depend greatly on the behavior of others. If no one or only few fishermen V-notch (strategy 0 in the model), then the number who V-notch eventually declines, because those who $\mathrm{V}$-notch will only be taken advantage of by free riders.

In the lobster fishery, that tipping point has been reached. Under these conditions, players cooperate and adhere to a high quality conservation practice (strategy 1 in the model) and V-notch widely. They have escaped the prisoner's dilemma, which is a difficult feat. This gives them high joint benefits (Axelrod 1984, Samuelson 2002, Gardner 2003, Dixit and Skeath 2004).

The question this raises is: How did V-notching start? Why should fishermen begin V-notching? Experience with evolutionary models shows it takes a major event, a shock, to move the system from one state to another. We believe that the shock of the lobster bust might have made enough fishermen start V-notching. Once the number had reached the critical adoption size, then more fishermen joined the effort. This, however, depended on a change in the culture of lobstering. Many fishermen would have had to be convinced that illegal behavior was detrimental to their own best interests, that enhancing the size of the breeding stock could be accomplished by preserving large females, and that $\mathrm{V}$-notching gave large, joint benefits (Acheson 2003, Acheson and Gardner 2010).

Second, the model indicates that fishermen engage in a high quality practice when the benefits of cooperating are higher than the benefits of staying with a poor-quality practice. In terms of the model, this is case 1 , where $b / n>c$. Only under these conditions do fishermen have a strong incentive to play their dominated strategy, i.e., V-notch (see Appendix 1). 
The ethnography indicates there are several kinds of costs and benefits involved. First, there are benefits in terms of larger catches that are likely to materialize in the future. These gains come far in the future and are shared by everyone. The extent of those benefits depends on the proportion of fishermen who V-notch. Second, those who Vnotch when everyone else is doing so get a benefit in terms of increased reputation. Fishermen who do not V-notch when many others are doing so suffer some loss in reputation. Third, fishermen who Vnotch get a psychic benefit for conserving the resource by ensuring a way of life for themselves and their communities. Fourth, everyone who Vnotches pays a cost in terms of time spent, but the costs are reasonably low. It only takes 30 seconds to V-notch a lobster, an average daily loss of 10 minutes.

\section{THE V-NOTCH IN THEORETICAL PERSPECTIVE}

\section{Standard explanations for escaping prisoner's dilemmas}

It is always difficult to solve prisoner's dilemmas. Unfortunately, the three most common explanations for why cooperation can occur in the face of a prisoner's dilemma do not explain the practice of $\mathrm{V}$-notching. The first explanation is a law or enforceable rule that forbids people from defecting. That is, the disastrous results of a prisoner's dilemma can be averted by a rule enforced by a third party that effectively changes the payoffs and makes defection unattractive (see Voss 2001). This does not apply in the case of the V-notch because there are no enforceable rules mandating $\mathrm{V}$-notching and no punishments for failing to $\mathrm{V}$-notch. The second explanation involves repeated play or an iterated game. If a prisoner's dilemma game is played once, it is only rational to defect (Axelrod 1984). If the game has no certain end and is played many times, however, then cooperation may be maintained with the use of the proper strategy, i.e., retaliation in kind ('tit for tat'), or the grim strategy. Tit for tat is effective in maintaining cooperation (Axelrod 1984, Nowak et al. 1995), but it does not characterize interactions concerning the V-notch. Fishermen do not know who is or is not V-notching, nor do they retaliate against fishermen who do not $\mathrm{V}$-notch. Non-V-notching fishermen might acquire a bad reputation among fishermen, but there is no way of sanctioning someone who does not contribute. The third explanation is leadership (Dixit and Skeath 2004), which can result in public goods being produced even if cooperation is minimal. In these cases, some players get so much from cooperation that they are willing to produce a public good even though others free ride off their efforts (see Olson 1965). However, this does not help to explain the $\mathrm{V}$-notch program because no group of fishermen gains more than any other from a larger stock size. All gain whether they contribute to the stock of V-notched lobsters or not. This means that fishermen are $\mathrm{V}$-notching because of personal commitment rather than from a fear of punishment.

\section{New approaches}

There is a growing amount of work on cooperation, however, that gives insight into the reasons that people may cooperate in the face of a prisoner's dilemma. There are two ideas stemming from new work on social evolution that are helpful in explaining $\mathrm{V}$-notching, one concerning reciprocity and the other the discount rate.

Axelrod (1984) argues that two factors can induce cooperation in a prisoner's dilemma game in addition to rules. One of these is altruism, which involves teaching people to put the welfare of others ahead of purely selfish gain. Another is reciprocity. Recently other authors have extended these ideas in ways that help to explain the reason many fishermen V-notch lobsters.

Nowak and Sigmund (2005) make a distinction between direct reciprocity and indirect reciprocity, or third-party altruism. Direct reciprocity is based on the principle "You scratch my back and I will scratch yours," so that both achieve a greater net benefit. Indirect reciprocity or third-party altruism refers to a situation in which there is no necessary reward for the people who help others: "You scratch my back and I will scratch someone else's" (Nowak and Sigmund 2005). The V-notch falls into the category of indirect reciprocity, and indirect reciprocity is difficult to understand. Nowak and Sigmund (2005) and Nowak (2006) stress that indirect reciprocity is rewarded by less tangible factors, including a reward in terms of greater reputation.

Gächter and Fehr (1999:341) have found that approval incentives such as better reputation "alone are not sufficiently strong to cause a reduction in 
free-riding." In combination with some minimal social familiarity, however, approval incentives generate a significant increase in cooperation and a reduction in free riding. Most lobstering communities have a long history. They are small, homogenous places with a strong sense of community. Many people in them know each other well. If the work of Gächter and Fehr is correct, it is in such communities that having a higher reputation could result in more cooperation and less free riding.

The discount rate, or what Axelrod (1984) calls the "shadow of the future," can influence the willingness to cooperate. He says that mutual cooperation can be stable if the future is sufficiently important relative to the present. According to Axelrod (1984:109), “in a Prisoner's Dilemma, the player has a short-run incentive to defect, but can do better in the long run by developing a pattern of mutual cooperation with the other." However, the player will only do this when he or she is convinced that the discounted benefits of future cooperation to be obtained over time outweigh the one time immediate benefits to be had from defection (see Dixit and Skeath 2004).

There are two factors that make lobster fishermen operate with a low discount rate and invest in the future. First, they are convinced that conserving the breeding stock results in greater future catches if enough people are involved. Second, they are convinced enough fishermen are $\mathrm{V}$-notching to produce those benefits. However, V-notching involves a leap of faith. There is nothing to ensure that a $\mathrm{V}$-notched lobster will ever produce eggs again, or that enough other fishermen are Vnotching to increase future catches appreciably. If this is true, then the underlying cause of $\mathrm{V}$-notching can be traced to cultural factors.

\section{CONCLUSION}

We argue that a number of factors combined to help fishermen overcome the prisoner's dilemma posed by the V-notch. Fishermen became convinced that protecting the large reproductive-sized lobsters effectively augmented the stock. Once a large number of fishermen began to $\mathrm{V}$-notch, there was a tangible reward in terms of larger future catches. As fishermen became increasingly certain of future good catches, they were more willing to invest in the industry. V-notching not only provided benefits to themselves, but joint benefits to the whole fishing community, with all that says about benefits to future generations and maintaining long-standing communities. Fishermen who $\mathrm{V}$-notch also gained in terms of reputation. These rewards outweighed the modest costs of $\mathrm{V}$-notching.

Solving the prisoner's dilemma, however, meant being willing to abandon the dominant strategy of maintaining poor quality practices (strategy 0) and playing the dominated strategy of high quality practices such as the V-notch (strategy 1). Ultimately, the development of $\mathrm{V}$-notching is traceable to cultural change. Fishermen needed to be convinced that conserving the breeding stock would increase the stock of lobsters and that others were $\mathrm{V}$-notching in appreciable numbers. There is little reason to $\mathrm{V}$-notch if recruitment of lobsters is not a function of breeding stock size and/or if the gains from $\mathrm{V}$-notching are going to free riders. Fishermen had to come to believe that V-notching was helping not only individuals, but the entire community in terms of future catches. They were willing to reward those who V-notched with esteem and increased reputation.

There are an increasing number of cases showing that people are far more cooperative than would be predicted based on game theory (Ostrom et al. 1994, Baland and Platteau 1996, Fehr and Gächter 2000, Henrich 2000, Camerer 2003). Henrich and colleagues state, "researchers from across the social sciences have found consistent deviations from the predictions of the canonical model of self interest in hundreds of experiments from around the world" (Henrich et al. 2005:795).

Another genre of ideas stemming from the concept of social preferences points to the same conclusion (Charness and Rabin 2002). The term social preferences refers to a situation in which a player's payoffs no longer depend just on his or her economic result, but more broadly on the overall outcome. In game theory, social preferences refers to the concern, or lack thereof, that people have for each other's welfare. It encompasses a variety of behaviors including altruism, reciprocity, an interest in equality and justice, and a willingness to punish those who deviate from norms or laws.

Recently, evolutionary theorists such as Henrich and Henrich, Boyd and Richerson, and those interested in social preferences have argued that culture plays a large role in determining game 
strategies leading to cooperation and the solution of collective action problems (Boyd and Richerson 2005, Henrich et al. 2005, Henrich and Henrich 2007). Of particular importance are changes in values and attitudes making resource users more willing to sacrifice current income for future income (Kortenkamp and Moore 2006). The idea that people might sacrifice for the common good by Vnotching does not appear quite so strange seen against the backdrop of these theories.

Responses to this article can be read online at: http://www.ecologyandsociety.org/voll6/iss1/art41/ responses/

\section{Acknowledgments:}

Roy Gardner died suddenly on January 10, 2011. He will be missed by all of those who worked with him. Thanks are due to the 701 lobster fishermen who took time to respond to our questionnaire in the spring of 2009. Special thanks are due to Bob Baines, Alison Bishop, Eddie Blackmore, Jimmy Brackett, Dan Cheney, Avery Chipman, Ralph Colby, Sarah Cotnoir, David Cousens, Michael Dawson, Edgar Drisko, Raymond Hamilton, Larry Knapp, Ken Prior, Brian Sawyer, Pat White, and Carl Wilson who answered hours of questions, and to Ann Acheson who supervised administration and data processing of the 2009 survey and who edited this paper. Support for the recent research reported here was provided by the National Science Foundation (Grant No. BCS-0821968, project title: 'Evolution of Norms and Conservation Rules in Two Fisheries').

\section{LITERATURE CITED}

Acheson, J. M. 1988. The lobster gangs of Maine. University Press of New England, Hanover, New Hampshire, USA.

Acheson, J. M. 1989. Management of common property resources. Pages 351-378 in S. Plattner, editor. Economic anthropology. Stanford University Press, Stanford, California, USA.

Acheson, J. M. 2003. Capturing the commons: devising institutions to manage the Maine lobster industry. University Press of New England, Hanover, New Hampshire, USA.

Acheson, J. M., and R. Gardner. 2010. Evolution of conservation rules and norms in the Maine lobster fishery. Ocean and Coastal Management 53:524-534.

Acheson, J. M., and J. Knight. 2000. Distribution fights, coordination games and lobster management. Comparative Studies in Society and History 42 (1):209-239.

Acheson, J. M., and R. Steneck. 1997. Bust and then boom in the Maine lobster fishery: perspectives of fishers and biologists. North American Journal of Fisheries Management 17:826-847.

Agrawal, A. 2002. Common resources and institutional sustainability. Pages 41-54 in E. Ostrom, T. Dietz, N. Dolsak, P. Stern, S. Stonich, and Elke Weber, editors. The drama of the commons. National Academy Press, Washington, D.C., USA.

Axelrod, R. 1984. The evolution of cooperation. Basic Books, New York, New York, USA.

Baland, J. M., and J. P. Platteau. 1996. Halting degradation of natural resources: is there a role for rural communities? Clarendon, Oxford, UK.

Boyd, R., and P. J. Richerson. 2005. Solving the puzzle of human cooperation. Pages 105-132 in S. Levinson, editor. Evolution and culture. MIT Press, Cambridge, Massachusetts, USA.

Camerer, C. F. 2003. Behavioral game theory: experiments in strategic interaction. Princeton University Press, Princeton, New Jersey, USA.

Charness, G., and M. Rabin. 2002. Understanding social preferences with simple tests. Quarterly Journal of Economics 117(3):817-869.

Coleman, J. 1990. Norm generating structures. Pages 250-272 in K. Cook and M. Levi, editors. The limits of rationality. University of Chicago Press, Chicago, Illinois, USA.

Correspondence of the Commissioner. Horatio Crie to Russell Turner, Sept 23, 1933. Maine State Archives, Augusta, Maine, USA. 
DeAngelis, B. M., R. Cooper, M. Clancy, C. Cooper, T. Angell, S. Olszewski, W. Colburn, and J. Catena. 2010. Impacts of v-notching the American lobster. Journal of Shellfish Research 29 (2):489-496.

Dixit, A., and S. Skeath. 2004. Games of strategy. Norton, New York, New York, USA.

Elster, J. 1989. The cement of society. Cambridge University Press, Cambridge, UK.

Fehr, E., and S. Gächter. 2000. Cooperation and punishment in public goods experiments. American Economic Review 90:980-995.

Gächter, S., and E. Fehr. 1999. Collective action as a social exchange. Journal of Economic Behavior and Organization 39:341-369.

Gardner, R. 2003. Games for business and economics. John Wiley and Sons, Hoboken, New Jersey, USA.

Gibson, M. R., and T. E. Angell. 2006. Estimating the reduction in fishing mortality on area 2 lobster associated with North Cape v-notching program. Rhode Island Division of Fish and Wildlife, Marine Fisheries Section, Jamestown, Rhode Island, USA.

Hardin, Garrett. 1968. The tragedy of the commons. Science 162:1243-1248.

Henrich, J. 2000. Decision making, cultural transmission and adaptation in economic anthropology. Pages 251-295 in J. Ensminger, editor. Theory in economic anthropology. Altamira Press, Walnut Creek, California, USA.

Henrich, J., R. Boyd, S. Bowles, C. Camerer, E. Fehr, H. Gintis, R. McElreath, M. Alvard, A. Barr, J. Ensminger, N. S. Henrich, K. Hill, F. Gil-White, M. Burven, F. Marlowe, J. Patton, and D. Tracer. 2005. 'Economic Man' in cross-cultural perspective: behavioral experiments in 15 small-scale societies. Behavioral and Brain Sciences 28:795-855.

Henrich, J., and N. Henrich. 2007. Why humans cooperate: a cultural and evolutionary explanation. Oxford University Press, New York, New York, USA.
Kelly, K. H. 1990. A summary of Maine lobster laws and regulations: 1820-1990. Department of Marine Resources Lobster Informational Leaflet \#19, Augusta, Maine, USA.

Knight, J. 1992. Institutions and social conflict. Cambridge University Press, Cambridge, UK.

Kortenkamp, K. V., and C. F. Moore. 2006. Time, uncertainty and individual differences in decisions to cooperate in resource dilemmas. Personal and Social Psychology Bulletin 32:603-615.

Laws of Maine. 1947. Chapter 332-A law to revise the sea and shore fisheries laws. Office of the Secretary of State, Augusta, Maine, USA.

Legislative Record. 1917. House, March 8, 1917, page 486. Maine Legislature, Augusta, Maine, USA.

Lewis, D. 1969. Convention: a philosophical study. Harvard University Press, Cambridge, Massachusetts, USA.

Lobster Institute. 1995. V-notching then, now and around the world. Lobster Bulletin 8(2):3. Lobster Institute, University of Maine, Orono, Maine, USA.

Lobster Technical Committee. 2000. Management measures that can be evaluated on an area-by-area basis. Report to the ASMFC American Lobster Board. Atlantic States Marine Fisheries Commission, Washington, D.C., USA.

Maine Commission of Sea and Shore Fisheries. 1926. Fourth biennial report of the Commission of Sea and Shore Fisheries of the state of Maine. Commission of Sea and Shore Fisheries, Rockland, Maine, USA.

Maine Department of Sea and Shore Fisheries. 1936. Ninth biennial report of the Department of Sea and Shore Fisheries of the state of Maine. Department of Sea and Shore Fisheries, Thomaston, Maine, USA.

Martin, K., and N. Lipfert. 1985. Lobstering and the Maine coast. Maine Maritime Museum, Bath, Maine, USA. 
McGoodwin, J. R. 1990. Crisis in the world's fisheries: people, problems and policies. Stanford University Press, Stanford, California, USA.

North, D. 1990. Institutions, institutional change and economic performance. Cambridge University Press, New York, New York, USA.

Nowak, M. 2006. Five rules for the evolution of cooperation. Science 314:1560-1563.

Nowak, M., and K. Sigmund. 2005. Evolution of indirect reciprocity. Nature 437:1291-1297.

Nowak, M., R. May, and K. Sigmund. 1995. The arithmetics of mutual help. Scientific American 272 (6):76-81.

Olson, M. 1965. The logic of collective action: public goods and the theory of groups. Harvard University Press, Cambridge, Massachusetts, USA.

Ostrom, E. 1990. Governing the commons: the evolution of institutions for collective action. Cambridge University Press, New York, New York, USA.

Ostrom, E. 2000a. Reformulating the commons. Swiss Political Science Review 61:29-52.

Ostrom, E. 2000b. Collective action and the evolution of social norms. Journal of Economic Perspectives 14:137-158.

Ostrom, E., R. Gardner, and J. Walker. 1994. Rules, games and common-pool resources. University of Michigan Press, Ann Arbor, Michigan, USA.

Plante, J. 1986. In Maine, it's been lobsters, lobsters, lobsters. Commercial Fisheries News April 18.

Poteete, A. R., M. A. Janssen, and E. Ostrom. 2010. Working together: collective action, the commons and multiple methods in practice. Princeton University Press, Princeton, New Jersey, USA.

Samuelson, L. 2002. Evolution and game theory. Journal of Economic Perspectives 16:47-66.

Sugden, R. 1986. The economics of rights, cooperation and welfare. Basil-Blackwell, London, UK.
Taylor, M. 1990. Cooperation and rationality: notes on the collective action problem and its solutions. Pages 222-249 in K. Cook and M. Levi, editors. The limits of rationality. University of Chicago Press, Chicago, Illinois, USA.

Thompson, B. 2000. Tragically difficult: the obstacles to governing the commons. Environmental Law 30:241-278.

Voss, T. 2001. Game-theoretic perspectives on the emergence of social norms. Pages 105-136 in M. Hechter and K.-D. Opp, editors. Social norms. Russell Sage Foundation, New York, New York, USA.

Wade, R. 1994. Village republics: economic conditions for collective action in South India. ICS Press, San Francisco, California, USA. 


\section{Appendix 1}

\section{A Three Parameter Model of Lobster Conservation Strategies}

To present the starkest choice imaginable, consider just two conservation strategies. Strategy 0 , a poor quality conservation practice, stands for the situation in the lobster industry before the V-notch was developed or became widespread.

Strategy 1, a high quality conservation practice, represents a better management scheme-i.e., when the V-notch was adopted by a large number of lobstermen.

Consider a set of $n$ fishermen. We normalize their payoffs from following strategy 0 to be zero. By contrast, if every fisherman follows strategy 1 , the benefit is b and the cost is c. Since strategy 1 represents better management, we have

$$
b-c>0
$$

It pays if every fisherman follows strategy 1.

If things were this simple, then the fishermen would just adopt strategy 1 and there would be no downward spiral. This is where the dilemma comes in.

Let $x_{i}$ be fisherman i's strategy, which takes on two values: $x_{i}=1$ if fisherman $i$ follows strategy 1 , and $x_{i}=0$ if $i$ follows strategy 0 . Finally, let $X$ be the sum of the $x_{i}$. This notation suffices to track the strategies employed in the game.

Let $\mathrm{u}_{\mathrm{i}}$ be fisherman i's payoff function.

$$
\begin{aligned}
u_{\mathrm{i}}=(X / n) b-c & \text { if } x_{\mathrm{i}}=1 \\
=(X / n) b & \text { if } x_{\mathrm{i}}=0 .
\end{aligned}
$$

The idea is that the full benefit b of following strategy 1 is only achieved if everyone in the fishery follows that rule. Otherwise, the benefit is proportional to the number following the rule. If everyone follows strategy 0 , then $X=0$, and the payoff for each fisherman is 0 . There are two cases to consider depending on whether $b / n>c$ or $b / n<c$.

In Case 1, b/n > c, fisherman i has an incentive to follow strategy 1 even if no one else does. His payoff is $(1 / n) b-c>0$, which is better than strategy 0 pays. This inequality applies to every player, and the result is a Nash equilibrium $\mathrm{x}^{*}$ of the game with $x^{*}{ }_{i}=1$ for every fisherman. The benefit to strategy 1 is so great that every fisherman adopts it. Fortunately in the Maine lobster industry this appears to be the case.

In Case $2 b / n<c$. Fisherman i has no incentive to follow strategy 1 if no one else does, since $(1 / n) b-c<0$, which he would get from following strategy 1 . So there is a Nash equilibrium $x^{*}$ with $x^{*}{ }_{i}=0$ for all $\mathrm{i}$. Plus, the same algebra applies to values of $\mathrm{x}$ greater than 0 . So the Nash equilibrium we have identified is unique. The fishermen are facing the prisoner's dilemma: $x^{*}{ }_{i}=0$ for all $\mathrm{i}$ is a strictly dominant strategy that leads to an inefficient outcome. 